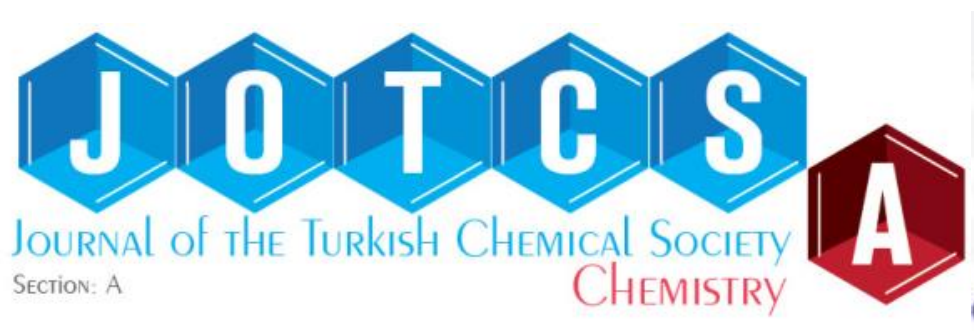

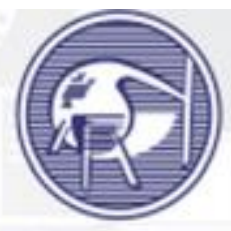

TURKISH

CHEMICAL SOCIETY

\title{
Examination of the Efficiency of Ionic Liquids in Glycolic Acid Separation from Aqueous Solution by Using Reactive Extraction Method
}

\author{
Yavuz Selim AŞÇI \\ İstanbul University, Engineering Faculty, Chemical Engineering Department, \\ 34320, İstanbul/Turkey
}

\begin{abstract}
In this study, the removal of glycolic acid from aqueous solutions by using reactive extraction with different organic solvents and tripropylamine mixtures was investigated. In experimental studies, methyl isobutyl ketone (MIBK), 1-decanol, toluene, cyclohexyl acetate (CHA), DMP, and an ionic liquid compound, namely 1-butyl-3-methylimidazolium hexafluorophosphate (IL), were chosen as the diluent solvent in the organic phase. In recent researches of chemistry, IL compounds have come to the foreground due to their superior properties and environmental friendly chemical structures and they are being used intensively. For this reason, it is particularly aimed to compare the efficiency of the IL compound with other solvents. In addition to the solvent effect, the amine concentration used was changed to determine the effect on extraction yield. Using the obtained data, the most important parameters for the design of reactive extraction processes were calculated: The distribution coefficient $(D)$, the loading factor $(Z)$, and the percentage of extraction efficiency (E\%).
\end{abstract}

Keywords: Reactive extraction, glycolic acid, ionic liquid.

Submitted: June 20, 2017. Accepted: September 23, 2017.

Cite this: Aşçı Y. Examination of the Efficiency of Ionic Liquids in Glycolic Acid Separation from Aqueous Solution by Using Reactive Extraction Method. JOTCSA. 2017;4(3):981-92.

DOI: $10.18596 /$ jotcsa. 322687.

*Corresponding author. E-mail: sasci@istanbul.edu.tr 


\section{INTRODUCTION}

Carboxylic acids are widely used in the pharmaceutical, cosmetic, textile, paper, food, and metal-cleaning industries. It also was found as the quality of raw materials in the production of many chemicals $(1,2)$.

Among the acids in carboxylic acid groups, glycolic acid, which is the most basic hydroxy carboxylic acid, has an important role. In recent years, it has become widely used in different sectors as well as becoming the most preferred skin care product agent in the field of cosmetics (3-5). Removal of glycolic acid from the reaction medium during the production is an important step in the process. Especially, in the fermentation method which is one of the most common way for glycolic acid production, only about $10 \%$ aqueous solution could be obtained. For this reason, there are many studies in literature and today's studies (6-8).

Several recovery processes are used for the recovery of carboxylic acids from their aqueous solutions such as electrodialysis, ion exchange, membrane separation, distillation, liquid-liquid extraction, and reactive extraction $(2,9)$. In these studies, reactive extraction method has the come into prominence because high dispersion coefficients can be obtained. Reactive extraction is based on the reaction between the solvent and the substance to be extracted. In this method, it reacts with carboxylic acid and reacting complex. In the reactive extraction process, amine compounds are generally used as the reactants. The choice of diluents is the most important parameter that influences the success of the treatment after the choice of reagent to be used. The types of diluents and, in particular, their functional groups, significantly affect the extraction behavior of the amines. The stoichiometry of the solution has a following effect: The amine complex can change the amine loading value and the third phase formation (10-14).

The scientists in the field of biotechnology and materials science are continuing to work on to make improvement in pivotal processes. Ionic liquids have become the most favorite chemical compound group in recent scientific work. The main applications of this compounds are their use as solvents in separation technologies and synthesis reactions due to their superior properties over classical solvents. In addition to the properties mentioned above, low toxic properties make ionic liquids more valuable for today's industry (15-19).

\section{THEORETICAL SECTION}

In the reactive extraction process, the reaction between glycolic acid $(H A)$ and TPA $\left(R_{3} N\right)$ can be expressed as the following (20): 


$$
\begin{aligned}
& \mathrm{i}(\mathrm{HA})^{\mathrm{R}}+\mathrm{j}\left(\mathrm{R}_{\mathrm{a}} \mathrm{N}\right)^{\mathrm{E}} \leftrightarrows\left((\mathrm{HA})_{\mathrm{i}} \cdot\left(\mathrm{R}_{3} \mathrm{~N}\right)_{\mathrm{j}}\right)^{\mathrm{E}}(\text { Eq. 1) } \\
& \mathrm{i}=1, \mathrm{p} ; \mathrm{j}=1, \mathrm{q}
\end{aligned}
$$

In the reaction, ()$^{R}$ represents the raffinate or water phase, ()$^{E}$ represents the extract or organic phase. The complex formed at the end of the reaction was shown in the organic phase. As no overloading of amine has been observed, it is expected to be less than or equal to $j$ for any $\mathrm{p}$ and $\mathrm{q}$.

When it is desired to extract glycolic acid from an aqueous medium using an amine compound mixed with the solvent, the term loading factor $(Z)$ is used to indicate the activity of the amine present in the organic phase. Loading factor $(Z)$ is the ratio of the acid concentration in the organic phase to the amine concentration in the organic phase (21-23).

$$
\mathrm{Z}=\frac{C_{a}}{C_{\text {e.org }}}
$$

In case of a dispersion of a substance between two solvents which are not mixed or slightly miscible with each other, the ratio of the equilibrium concentrations between these two phases gives the diffusion coefficient and is determined as the following:

$$
\mathrm{D}=\frac{C_{a, 0 r g}}{C_{a}}
$$

The extraction efficiency, $E$, is given as

$$
\mathrm{E}=\left(1-\left(\frac{C_{a}}{C_{a 0}}\right) \times 100\right.
$$

In this equation, $\mathrm{C}_{\mathrm{a}}$ is the initial acid concentration and $\mathrm{C}_{\mathrm{a}}$ is the acid concentration in the water phase after extraction. An E value of $100 \%$ means that the acid in the aqueous phase has been fully separated from aqueous phase to organic phase $(14,24)$.

\section{EXPERIMENTAL SECTION}

The purity and density of the chemicals used in the experiments and the companies to which they are purchased are presented in Table 1. 
Table 1: The purity of substances studied and their physical properties at $298.2 \mathrm{~K}$.

\begin{tabular}{cccc}
\hline Substance & Source & Purity & $\rho_{\mathbf{r}}\left(\mathbf{k g} / \mathbf{m}^{\mathbf{3}} \mathbf{)}\right.$ \\
\hline Water & $\begin{array}{c}\text { Deionized } \\
\text { and } \\
\text { distilled }\end{array}$ & & 997 \\
TPA & Merck & $>98 \%$ & \\
Glycolic acid & Merck & $70 \%$ solution in water & 1416 \\
DMP & Merck & $>99 \%$ & 1257 \\
MIBK & Merck & $>99 \%$ & 800 \\
Toluene & Carlo-Erba & $>99 \%$ & 867 \\
1-decanol & Sigma-aldrich & $>99 \%$ & 830 \\
CHA & Sigma-aldrich & $>99 \%$ & 970 \\
IL & Io-li-tec & $>99 \%$ & 1380 \\
\hline
\end{tabular}

Experiments were carried out by preparing a solution of glycolic acid in pure water at a concentration of $1.57 \mathrm{~mol} / \mathrm{L}(\mathrm{w} / \mathrm{w}=10.7 \%)$. In the first step, conventional extraction was carried out and the glycolic acid solution was treated with pure solvents. After these experiments, reactive extraction experiments were carried out. Tripropylamine was used as the reagent. Solutions of tripropylamine in selected solvents at concentrations of $0.35,0.70,1.05$, 1.40 , and $1.75 \mathrm{~mol} / \mathrm{L}$ were prepared. Extraction was carried out in $3 \mathrm{~mL}$ equal volumes of acid solutions and the organic phase mixture was taken up in $50 \mathrm{~mL}$ volume glass flasks. These flasks have been shaken in a Nuve Shaker ST30 thermostated bath at $298.15 \mathrm{~K}$ for $2 \mathrm{~h}$, which has been shown to be a sufficient time for extraction equilibria. After the extraction is complete and the phase transitions are balanced, these examples were centrifuged by nuve CN180 machine in $2000 \mathrm{rpm}$ for another $20 \mathrm{~min}$. to reach full separation of phases.

\section{RESULTS AND DISCUSSION}

In experimental studies, the effect of solvent selection on separation of glycolic acid by aqueous extraction from aqueous solutions was investigated. It is aimed to determine the effectiveness of ionic liquids in this process. For this purpose, it was chosen to compare it with the solvent ionic liquid of different structure which is frequently used in past studies with reactive extraction $(21,22,25)$. This solvent was selected from the ones having ester group (DMP and CHA), ketone group (MIBK), alcohol group (1-decanol), and aromatic hydrocarbon group (toluene).

The classical extraction process is based on the distribution of a substance between two phases (26). The success of the selected solvents in the conventional extraction process was investigated. The distribution of glycolic acid in water and pure solvents is presented in Table 2. In addition, E\% of pure solvents is shown in Figure 1. 
Table 2: Distribution of glycolic acid between solvents and water at $25^{\circ} \mathrm{C}$ and $1 \mathrm{~atm}$.

\begin{tabular}{lcccc}
\hline Diluent & $\begin{array}{c}\left(\mathbf{C}_{\mathbf{a}} \mathbf{R}^{\mathbf{R}}\right. \\
(\mathbf{m o l} / \mathbf{L})\end{array}$ & $\begin{array}{c}\left.\mathbf{( C}_{\mathbf{a}}\right)^{\mathbf{E}} \\
(\mathbf{m o l} / \mathbf{L})\end{array}$ & $\mathbf{D}$ & $\begin{array}{c}\mathbf{E} \\
(\mathbf{\%})\end{array}$ \\
\hline DMP & 1.51 & 0.07 & 0.04 & 4.14 \\
\hline MIBK & 1.47 & 0.10 & 0.07 & 6.22 \\
\hline 2-octanone & 1.46 & 0.11 & 0.08 & 7.04 \\
\hline 1-decanol & 1.46 & 0.11 & 0.07 & 6.94 \\
\hline CHA & 1.48 & 0.09 & 0.06 & 5.49 \\
\hline IL & 1.43 & 0.14 & 0.10 & 8.70 \\
\hline
\end{tabular}

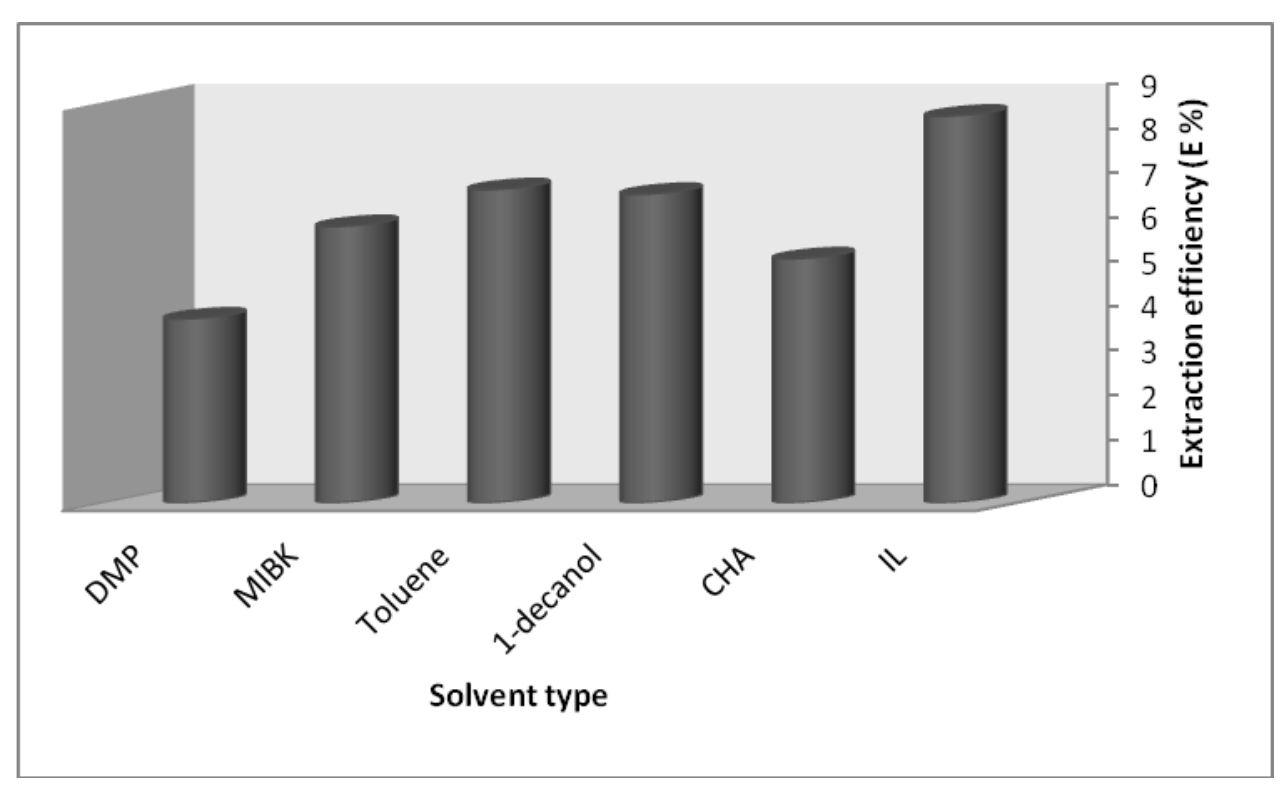

Figure 1: Extraction efficiency of glycolic acid between water and pure solvents used in this study.

The maximum extraction efficiency for glycolic acid has been obtained with IL (87.0\%). Conventional extraction seems to be inefficient even with the best result, IL. This is due to the high affinity of glycolic acid for water and low relative volatility. That is, a low distribution coefficient is observed because the solubility tendency in water is higher than in organic solvents. Traditional extraction techniques are therefore not suitable $(27,28)$.

Table 3 and Figure 2 shows the equilibrium data on the distribution of glycolic acid between water and organic phase for amine concentrations ranging from $0.35 \mathrm{~mol} / \mathrm{L}$ to $1.75 \mathrm{~mol} / \mathrm{L}$ for each solvent. 
Table 3: Experimental results of the extraction of glycolic acid with TPA/individual diluting solvents at $25^{\circ} \mathrm{C}$ and $1 \mathrm{~atm}$.

\begin{tabular}{|c|c|c|c|c|c|c|}
\hline Diluent & $\begin{array}{c}\left(\mathrm{C}_{\mathrm{e}}\right)^{\mathrm{E}} \\
(\mathrm{mol} / \mathrm{L})\end{array}$ & $\begin{array}{c}\left(C_{a}\right)^{R} \\
(\mathrm{~mol} / \mathrm{L})\end{array}$ & $\begin{array}{c}\left(\mathrm{C}_{a}\right)^{\mathrm{E}} \\
(\mathrm{mol} / \mathrm{L})\end{array}$ & D & $\mathbf{Z}$ & $\begin{array}{c}E \\
(\%)\end{array}$ \\
\hline \multirow[t]{5}{*}{ DMP } & 0.35 & 1.026 & 0.544 & 0.53 & 1.553 & 34.63 \\
\hline & 0.70 & 0.672 & 0.898 & 1.34 & 1.283 & 57.22 \\
\hline & 1.05 & 0.332 & 1.238 & 3.73 & 1.179 & 78.88 \\
\hline & 1.40 & 0.036 & 1.534 & 43.10 & 1.096 & 97.73 \\
\hline & 1.75 & 0.005 & 1.565 & 290.10 & 0.894 & 99.66 \\
\hline \multirow[t]{5}{*}{ MIBK } & 0.35 & 1.037 & 0.533 & 0.51 & 1.523 & 33.95 \\
\hline & 0.70 & 0.646 & 0.924 & 1.43 & 1.321 & 58.88 \\
\hline & 1.05 & 0.361 & 1.209 & 3.35 & 1.152 & 77.02 \\
\hline & 1.40 & 0.065 & 1.505 & 23.25 & 1.075 & 95.88 \\
\hline & 1.75 & 0.009 & 1.561 & 169.45 & 0.892 & 99.41 \\
\hline \multirow[t]{5}{*}{ Toluene } & 0.35 & 1.017 & 0.553 & 0.54 & 1.580 & 35.21 \\
\hline & 0.70 & 0.627 & 0.943 & 1.51 & 1.347 & 60.08 \\
\hline & 1.05 & 0.311 & 1.259 & 4.05 & 1.199 & 80.20 \\
\hline & 1.40 & 0.032 & 1.538 & 48.63 & 1.099 & 97.99 \\
\hline & 1.75 & 0.014 & 1.556 & 107.43 & 0.889 & 99.08 \\
\hline \multirow[t]{5}{*}{ 1-Decanol } & 0.35 & 1.011 & 0.559 & 0.55 & 1.597 & 35.60 \\
\hline & 0.70 & 0.604 & 0.966 & 1.60 & 1.380 & 61.54 \\
\hline & 1.05 & 0.305 & 1.265 & 4.14 & 1.204 & 80.55 \\
\hline & 1.40 & 0.026 & 1.544 & 58.58 & 1.103 & 98.32 \\
\hline & 1.75 & 0.008 & 1.562 & 197.88 & 0.893 & 99.50 \\
\hline \multirow[t]{6}{*}{ CHA } & 0.35 & 1.020 & 0.550 & 0.54 & 1.571 & 35.02 \\
\hline & 0.70 & 0.643 & 0.927 & 1.44 & 1.325 & 59.06 \\
\hline & 1.05 & 0.358 & 1.212 & 3.39 & 1.495 & 77.20 \\
\hline & 1.40 & 0.037 & 1.533 & 41.52 & 1.095 & 97.65 \\
\hline & 1.75 & 0.008 & 1.562 & 197.88 & 0.893 & 99.50 \\
\hline & 0.35 & 1.019 & 0.551 & 0.54 & 1.575 & 35.12 \\
\hline \multirow[t]{4}{*}{ IL } & 0.70 & 0.634 & 0.936 & 1.48 & 1.337 & 59.62 \\
\hline & 1.05 & 0.319 & 1.251 & 3.92 & 1.191 & 79.67 \\
\hline & 1.40 & 0.018 & 1.552 & 84.17 & 1.108 & 98.83 \\
\hline & 1.75 & 0.004 & 1.566 & 410.60 & 0.895 & 99.76 \\
\hline
\end{tabular}




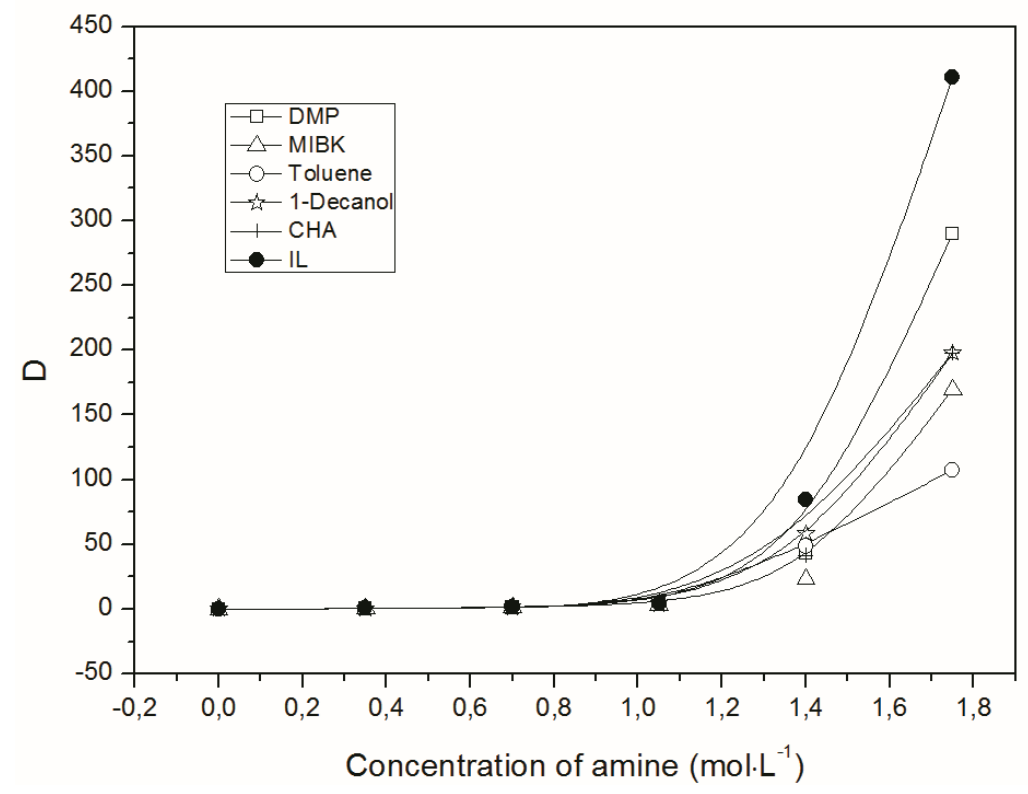

Figure 2: Distribution coefficients (D) of glycolic acid with concentration of amine in different individual diluting solvents.

It has been observed that the increase in the concentration of amines in the outcome leads to the increase in the value of distribution coefficient in all solvents. The highest value was calculated as 99.76 in IL for an amine concentration of $1.75 \mathrm{~mol} / \mathrm{L}$.

The extraction efficiencies of the solvents based on the obtained results (for $1.75 \mathrm{~mol} / \mathrm{L}$ amine concentration) can be listed as follows:

$\operatorname{IL}(99.76 \%)>\operatorname{DMP}(99.66 \%)>\operatorname{CHA}(99.50 \%)=1$-decanol $(99.50 \%)>\operatorname{MIBK}(99.41 \%)>$ Toluene $(99.08 \%)$

Figure 3 presents the variation between loading factors for varying concentrations of solvents and amines. The loading curve is a plot of $Z$ vs amine concentration. When the variation of the $Z$ parameters is evaluated, two situations could be discussed. As the amine concentrations increase, the loading factor values increase too. This is called overloading (loading greater than unity) and indicates that complexes with more than one acid per amine have been formed. The other is that the loading factor values decrease with increasing amine concentration and indicating that complexes include the diluents specifically interacting with complexes include more than one amine per complex (29). It is clear from the results in Figure 3 that the decrease in loading factor values is observed for all solvents in this study. 


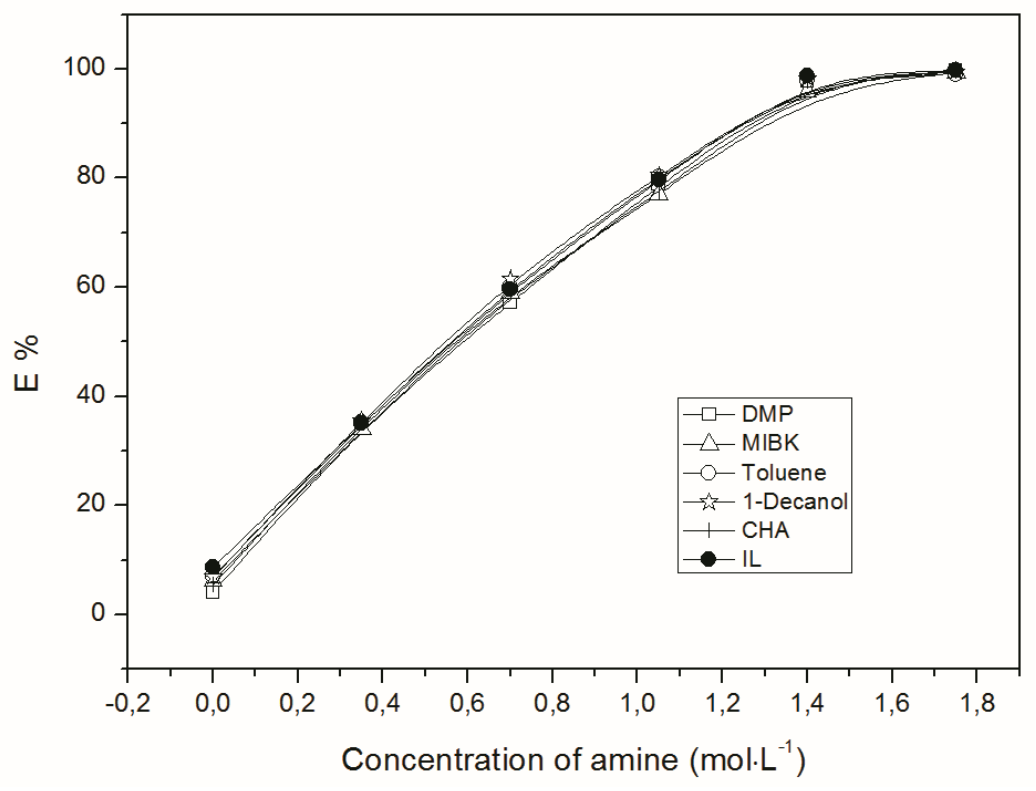

Figure 3: Loading factors $(Z)$ of glycolic acid with concentration of amine in different individual diluting solvents.

Extraction efficiency values (E\%) obtained by amine concentration changes are presented in Figure 4. This parameter is important to understand at first sight the success of working in reactive extraction experiments. When E\% values are examined in this study, it appears that almost all of the glycolic acid is separated from the aqueous medium. It was also found that the best results were obtained when used as an IL solvent (26).

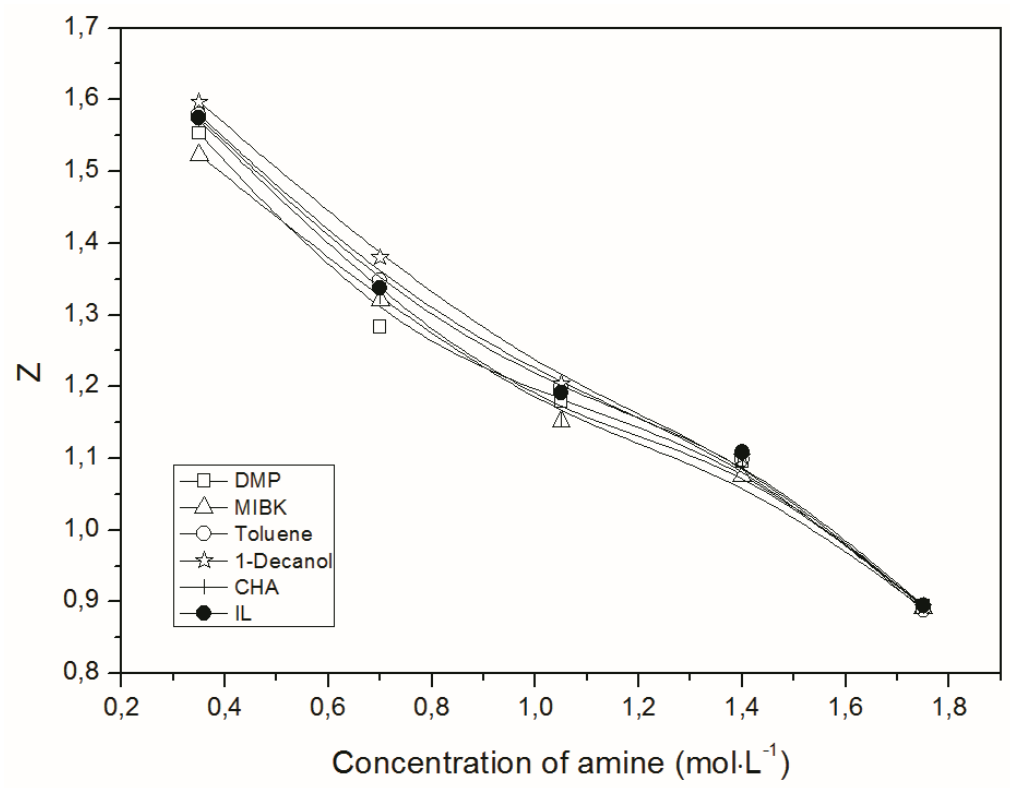

Figure 4: Extraction efficiency (E\%) of glycolic acid with concentration of amine in different individual diluting solvents. 


\section{CONCLUSIONS}

In the study, the success of the reactive extraction process was investigated in removing glycolic acid from aqueous solutions. In the conventional extraction experiments, it was seen that the E\% values were less than $10 \%(4.14 \%-8.69 \%)$ and the distribution coefficient values were found less than $0.1(0.04-0.1)$ for all solvents. Distribution coefficients were reached to 410.60 in the reactive extraction process, an alternative to the classical extraction method, and nearly all (> 99\%) of glycolic acid in all solvents could be separated from the aqueous phase. Compared with the efficiency of different solvents, 1-butyl-3methylimidazolium hexafluorophosphate (BMIMPF6) compound used in the ionic liquid group showed the best results both in the conventional extraction and reactive extraction process, especially at high amine concentrations. In the light of these evaluations, it can be said that ionic liquids should be used for reactive extraction processes as an environmentally friendly solvent and BMIMPF6 has superior properties which can be preferred for separating glycolic acid as a solvent from aqueous medium.

\section{ACKNOWLEDGMENTS}

This work was supported by the Istanbul University Scientific Research Project Department. Project Number BEK-2016-21775.

\section{SYMBOLS AND ABBREVIATIONS}

$\begin{array}{ll}\text { BMIMPF6 } & \text { - 1-Butyl-3- methylimidazolium hexafluorophosphate } \\ \left(\mathrm{C}_{a}\right)^{\mathrm{R}} & \text { - Concentration of acid in the aqueous phase, mol/L } \\ \left(\mathrm{C}_{a}\right)^{\mathrm{E}} & \text { - Concentration of acid in the organic phase, mol/L } \\ \left(\mathrm{C}_{e}\right)^{\mathrm{E}} & \text { - Concentration of amine in the organic phase, mol/L } \\ \mathrm{CHA} & \text { - Cyclohexyl acetate } \\ \text { D } & \text { - Distribution coefficient } \\ \text { DMP } & \text { - Dimethyl phthalate } \\ E & \text { - The efficiency of extraction } \\ \text { HA } & \text { - Glycolic acid } \\ \text { IL } & \text { - Ionic liquid (BMIMPF6) } \\ \text { MIBK } & \text { - Methyl isobutyl ketone } \\ p & \text { - Number of acid molecules } \\ q & \text { - Number of amine molecules } \\ \text { R3N } & \text { - Tertiary amine } \\ W & \text { - Mass fraction } \\ Z & \text { - Loading factor } \\ ()^{\mathrm{E}} & \text { - Organic phase } \\ ()^{\mathrm{R}} & \text { - Aqueous phase }\end{array}$

\section{REFERENCES}

1. Bayazit SS, Inci Is, Uslu H. Adsorption of Glutaric Acid and Glyoxylic Acid onto Weakly Basic IonExchange Resin: Equilibrium and Kinetics. Journal of Chemical \& Engineering Data. 2009;55(2):679-84. 
2. Asci YS, Hasdemir IM. Removal of Some Carboxylic Acids from Aqueous Solutions by Hydrogels. J Chem Eng Data. 2008;53(10):2351-5.

3. Datta D, Kumar S. Reactive extraction of glycolic acid using tri-n-butyl phosphate and tri-n-octylamine in six different diluents: Experimental data and theoretical predictions. Ind Eng Chem Res. 2011;50(5):3041-8.

4. Datta D, Kumar S. Modeling using response surface methodology and optimization using differential evolution of reactive extraction of glycolic acid. Chem Eng Commun. 2015;202(1):59-69.

5. Uslu H, Datta D, Kumar S. Reactive Extraction of Oxoethanoic Acid (Glyoxylic Acid) Using AmberliteLA2 in Different Diluents. Journal of Chemical \& Engineering Data. 2014;59(8):2623-9.

6. Tuyun $A F$, Uslu $H$. Investigation of picolinic acid extraction by trioctylamine. Int J Chem React Eng. 2011;9:A29.

7. Tuyun AF, Uslu H. Reactive extraction of cyclic polyhydroxy carboxylic acid using trioctylamine (TOA) in different diluents. Journal of Chemical \& Engineering Data. 2012;57(8):2143-6.

8. Aljundi IH, Belovich JM, Talu O. Adsorption of lactic acid from fermentation broth and aqueous solutions on Zeolite molecular sieves. Chemical Engineering Science. 2005;60(18):5004-9.

9. Datta D, Asci YS, Tuyun AF. Extraction Equilibria of Glycolic Acid Using Tertiary Amines: Experimental Data and Theoretical Predictions. J Chem Eng Data. 2015;60(11):3262-7.

10. Wasewar KL, Shende D, Keshav A. Reactive extraction of itaconic acid using quaternary amine Aliquat 336 in ethyl acetate, toluene, hexane, and kerosene. Ind Eng Chem Res. 2010;50(2):1003-11.

11. Tamada JA, King CJ. Extraction of carboxylic acids with amine extractants. 2. Chemical interactions and interpretation of data. Ind Eng Chem Res. 1990;29(7):1327-33.

12. Yankov D, Molinier J, Albet J, Malmary G, Kyuchoukov G. Lactic acid extraction from aqueous solutions with tri-n-octylamine dissolved in decanol and dodecane. Biochemical Engineering Journal. $2004 ; 21(1): 63-71$.

13. Qin W, Li Z, Dai Y. Extraction of monocarboxylic acids with trioctylamine: equilibria and correlation of apparent reactive equilibrium constant. Ind Eng Chem Res. 2003;42(24):6196-204.

14. Bízek V, Horáček J, Koušová M. Amine extraction of citric acid: effect of diluent. Chemical Engineering Science. $1993 ; 48(8): 1447-57$.

15. Galán-Cano F, Lucena R, Cárdenas S, Valcárcel M. Dispersive micro-solid phase extraction with ionic liquid-modified silica for the determination of organophosphate pesticides in water by ultra performance liquid chromatography. Microchem J. 2013;106:311-7.

16. Vander Hoogerstraete T, Wellens S, Verachtert K, Binnemans K. Removal of transition metals from rare earths by solvent extraction with an undiluted phosphonium ionic liquid: separations relevant to rare-earth magnet recycling. Green Chemistry. 2013;15(4):919-27.

17. Santos E, Albo J, Irabien A. Acetate based supported ionic liquid membranes (SILMs) for CO 2 separation: influence of the temperature. Journal of membrane science. 2014;452:277-83.

18. Jiang W, Zhu W, Li H, Wang X, Yin S, Chang Y, et al. Temperature-responsive ionic liquid extraction and separation of the aromatic sulfur compounds. Fuel. 2015;140:590-6.

19. Goossens K, Lava K, Bielawski CW, Binnemans K. Ionic liquid crystals: versatile materials. Chemical reviews. $2016 ; 116(8): 4643-807$.

20. Tamada JA, King C. Extraction of carboxylic acids by amine extractants. Lawrence Berkeley Lab., CA (USA); 1989.

21. Maurer G. Modeling the liquid-liquid equilibrium for the recovery of carboxylic acids from aqueous solutions. Fluid Phase Equilibr. 2006;241(1):86-95.

22. Rodriguez M, Gonzalez-Munoz M, Luque S, Alvarez J, Coca J. Extractive ultrafiltration for the removal of carboxylic acids. Journal of membrane science. $2006 ; 274(1): 209-18$. 
23. Tamada JA, King C. Extraction of carboxylic acids with amine extractants. III: Effect of temperature, water coextraction, and process considerations. Ind Eng Chem Res. 1990;29(7):1333-8.

24. Hong $Y$, Hong W. Extraction of succinic acid with 1-octanol/n-heptane solutions of mixed tertiary amine. Bioprocess and Biosystems Engineering. 2000;23(5):535-8.

25. Kuzmanović B, Kuipers NJ, de Haan AB, Kwant G. Reactive extraction of carboxylic acids from apolar hydrocarbons using aqueous solutions of sodium hydrogen carbonate with back-recovery using carbon dioxide under pressure. Sep Purif Technol. 2005;47(1):58-72.

26. King CJ. Separation processes: Courier Corporation; 2013.

27. Asci YS, Inci I. Extraction of Glycolic Acid from Aqueous Solutions by Amberlite LA-2 in Different Diluent Solvents. J Chem Eng Data. 2009;54(10):2791-4.

28. Inci I, Bayazit SS, Asci YS. Solid-liquid equilibrium of glycolic acid with alumina. Desalin Water Treat. 2015;56(11):3122-7.

29. Bayazit SS, Uslu H, İnci İ. Comparative equilibrium studies for citric acid by amberlite LA-2 or Tridodecylamine (TDA). Journal of Chemical \& Engineering Data. 2009;54(7):1991-6. 
